\title{
Palabra escrita, espacio público y política en Clorinda Matto de Turner
}

Recibido: 05/02/2020

Aprobado: 04/03/2020

Publicado Online: 20/07/2020

\author{
MARÍA EMMA MANNARELLI \\ Universidad Nacional Mayor de San Marcos \\ mannarellil1@gmail.com \\ DAVID VELÁSQUEZ \\ Universidad Nacional Mayor de San Marcos \\ dvelasquezs@unmsm.edu.pe
}

\begin{abstract}
RESUMEN
El presente artículo aborda la participación pública y política de Clorinda Matto de Turner desde la palabra escrita en las postrimerías del Perú del siglo XIX. El analizar este personaje implica abordar las complejas y a veces contradictorias apuestas que los intelectuales peruanos —en este caso, una mujerhicieron para alcanzar la modernidad en dicho período y las resistencias que los grupos conservadores impusieron a estas vanguardias letradas. Empleando sus novelas y artículos periodísticos, abordamos la trayectoria intelectual de Clorinda Matto en las décadas de 1880 y 1890, observando sus propuestas de modernización de la vida pública, en especial, sus planteamientos sobre la educación femenina, que le granjearon la oposición clerical y conservadora, y que terminaron motivando su participación en la vida política, desde la prensa, y finalmente su exilio.
\end{abstract}

Palabras clave: Clorinda Matto de Turner, Palabra escrita, Política, Modernidad, Prensa.

\section{Written word, public space and politics in Clorinda Matto de Turner}

\begin{abstract}
This article addresses the public and political participation of Clorinda Matto de Turner, from the written word, in the late nineteenth-century Peru. Analyzing this character implies to tackle the complex and at times contradictory risks that Peruvian intellectuals - in this case, a woman - took towards modernity in said period, and the resistance imposed by conservative groups on these literary avant-gardes. Using her novels and newspaper articles, we addressed the intellectual career of Clorinda Matto in the 1880s and 1890s, considering her proposals for the modernization of public life. In particular, her approaches to female education, which earned her the clerical and conservative opposition that ended up motivating her participation, from the press, in political life, and finally, her exile.
\end{abstract}

Keywords: Clorinda Matto de Turner, Written word, Politics, Modernity, Press. 


\section{Introducción}

Clorinda Matto de Turner es una de las escritoras peruanas más estudiadas. La fascinación de académicos e intelectuales por su obra estuvo centrada en el carácter realista y político-social de sus novelas, especialmente el carácter de denuncia sobre las condiciones de explotación en el Perú rural de finales del siglo XIX, destacando por ello Aves sin nido (1889) como su novela más importante, de acuerdo con la crítica académica. La producción escrita de Clorinda y su propia vida siguen provocando acercamientos del más variado tipo. Lo que Matto pensó, hizo y escribió no deja de animar intereses y preguntas desde la literatura, los estudios culturales, la historia y los estudios de género. ${ }^{1}$

En este, artículo nos acercamos a su trayectoria pública y política destacando su relación con la palabra escrita en el entramado de conflictos y contradicciones que generó la modernización tardo-decimonónica. Proponemos observar su propuesta modernizadora en relación con la vida social y cultural peruana iniciada en la prensa intelectual y la novela, que luego la llevará a participar activamente en la lucha política peruana hasta 1895 , fecha en la que su imprenta La Equitativa es destruida a manos de las montoneras pierolistas, y su inmediato y definitivo exilio. Analizar este tránsito y su final abrupto requiere comprender a la escritora como un personaje complejo, con contradicciones propias, inserto en un contexto de cambios y resistencias, en el que las mujeres - como es el caso elocuente de Clorinda — buscaron participar en el espacio público haciendo uso de la palabra escrita, no sin hacer apuestas y asumir los riesgos y costos que imponía la inestabilidad propia de lucha entre los caudillos, pero, sobre todo, la gravitación de las fuerzas conservadoras.

Teniendo como eje la palabra escrita, seguimos su itinerario intelectual y periodístico durante las décadas de 1880 y 1890; discutimos su propuesta vanguardista expuesta en su posición anticlerical y su apuesta por la educación de la población indígena y de las mujeres. Luego, tratamos su proyecto editorial manifiesto en su imprenta La Equitativa y la fundación de su periódico Los Andes, así como su apuesta por el caudillo militar Andrés Avelino Cáceres, identificado por la autora como el personaje que encarnaba el patriotismo y el bien común.

1 Solo para mencionar algunas contribuciones de las muchas que se han escrito respecto de Clorinda Matto de Turner, tenemos Fanny Arango-Keeth (2016, 2012), Anna Peluffo (2005), Mary G. Berg (2010, 1997), Ana María Portugal (1999), Rocío Ferreira (con "La profesionalización de la periodista y escritora: Clorinda Matto de Turner obrera del pensamiento"), Francesca Denegri (2004) y Evelyn Sotomayor (2014). 
Concluimos el artículo con la reflexión que hizo la propia Matto sobre los hechos de violencia de la guerra civil de 1895 y la destrucción de La Equitativa, ensayando las explicaciones de este hecho a la luz de su trayectoria individual, el contexto de violencia política y las presiones de los grupos conservadores que acompañaron a Nicolás de Piérola, rival por antonomasia de Cáceres.

\section{Clorinda Matto, una trayectoria individual}

Clorinda Matto de Turner nació en Cusco, el 11 de setiembre de 1852, en una familia notable y acomodada. Su infancia transcurrió entre la hacienda familiar Paullo-Chico en la provincia cusqueña de Calca y la ciudad imperial, en donde asistió al Colegio de Educandas. En 1871, tras casarse con el comerciante y médico inglés Joseph Turner, se estableció en Tinta, desde donde escribe precozmente para publicaciones como El Heraldo, El Ferrocarril, El Rodadero, El Eco de los Andes y El Mercurio. Sin las demandas de la maternidad, Matto materializa entre 1876 y 1877 en Cusco su primer proyecto editorial, la revista $E l$ Recreo, dedicada a la literatura, ciencias, artes y educación. Durante este período, Clorinda se convierte en animadora de un espacio de reunión para la intelectualidad cusqueña, conocido con el nombre de las Veladas, el cual por su ambiente de curiosidad y discusión le vale el desafecto de los grupos conservadores y católicos de una ciudad con una elite empobrecida y atada a las glorias del pasado.

Su visita a Lima en 1877 cierra este período, y en la capital participa en las tertulias literarias organizadas por la escritora salteña Juana Manuela Gorriti, por quien Clorinda siempre mostró admiración y afecto. El potente y fructífero entorno literario nucleado en torno a Gorriti recibió positivamente a la escritora cusqueña y le proveerá de claves para lo venidero. Pocos años más tarde se inicia la guerra del Pacífico (1879-1883), años que le deparan una serie de infortunios: en 1881 falleció su esposo y la quebrantada fortuna familiar la obliga a trasladarse nuevamente a Tinta para responsabilizarse personalmente de su casa comercial (Basadre, 1969, pp. 40-43). Los acontecimientos desastrosos de la guerra le son particularmente sentidos y dejarían — como a muchos intelectuales de su generación - ingratos recuerdos que marcaron su modo de vivir la política.

Equilibrada la situación familiar, Clorinda asume a fines de 1883 la jefatura de redacción La Bolsa en Arequipa, lo que la convierte en la primera mujer 
directora de un diario en el continente. Por esos años, Clorinda es testigo de ocasión de los estertores de la guerra externa y los aprestos del entonces coronel Andrés Avelino Cáceres para deponer al coronel Miguel Iglesias, en la guerra civil derivada de la conflagración con Chile. En esta época son publicadas sus Tradiciones cuzqueñas, obra que comenzó a escribir durante la década de 1870, inspirada en su temprano mentor y amigo Ricardo Palma. Ya restablecida la paz, en abril de 1886 se radica en Lima y se convierte en animadora del Círculo Literario y del Ateneo de Lima, grupo que congregó a parte importante de la intelectualidad liberal capitalina. Ese año apareció una segunda serie de sus Tradiciones cuzqueñas.

En 1889 es ya una de las intelectuales más prestigiosas del país; ese año asume la dirección de El Perú Ilustrado, la revista literaria más importante de Lima, y salen a la luz dos libros suyos: el primero, una serie de descripciones histórico biográficas, bajo el título de Bocetos al lápiz de americanos célebres, y el segundo, Aves sin nido, su primera y ambiciosa novela en la que denuncia la corrupción de los funcionarios del Estado y el clero, y su connivencia para la explotación del campesinado indígena. En 1889 publica en los talleres de La Bolsa un folleto titulado Elementos de Literatura según el Reglamento de Instrucción Pública para uso del bello sexo, en donde Matto expuso sus propuestas para la educación de las mujeres.

Los siguientes años son claroscuros para su carrera: mientras que en $E l$ Perú Ilustrado publicó la obra de muchos escritores consagrados, entre estos, Rubén Darío, Manuel González Prada y varios de los integrantes del grupo literario que se reunía con regularidad en su casa, consolidando así la respetabilidad y aprecio de intelectuales y escritores liberales, positivistas y librepensadores; también sufre los ataques del clero y asociaciones procatólicas enfurecidas por la publicación en 1890 del cuento "Magdala" — del cual se hablará más adelante- y por la denuncia explícita de la corrupción del clero presente en su primera y controversial novela. Las presiones de este grupo lograron que renunciara a la revista en 1891, aunque no por ello cejó en exponer la venalidad eclesiástica en su segunda novela Índole en el mismo año.

En 1892, Matto funda en Lima La Equitativa, imprenta que empleó a mujeres y que publicó el bisemanal Los Andes desde donde apoyó al general Andrés Avelino Cáceres y su Partido Constitucional. Fueron estos los años en los que la autora hace explícita su vocación y principios políticos que la enemista con las elites políticas opositoras a Cáceres, quienes se harían del poder luego de una cruenta guerra civil. En 1895 estos grupos, al mando de 
Nicolás de Piérola, tomaron Lima y saquearon la casa de Matto y destruyeron su imprenta. Ante un ambiente hostil, la asediada escritora se embarcó hacia Valparaíso, y luego se estableció en Buenos Aires. En Lima, ese año había publicado Herencia, obra que describe las ambivalencias de la elite limeña frente a los procesos de modernización del país; pocos años después de Hima-Sumac y Leyendas y recortes, obras que fueron editadas en su propia imprenta, en 1892 y 1893 respectivamente. Ya en el exilio en Buenos Aires, en 1896 fundó la revista Búcaro Americano, donde publica a escritores como Ricardo Palma, Amado Nervo, Rubén Darío o Leopoldo Lugones. Colaboró en otros medios, como La Nación, El Tiempo y La Razón. Fue profesora en la Escuela Normal de la Capital Federal, en la Escuela Normal Norteamericana y en la Escuela Comercial de Mujeres. En 1908 viajó a diferentes países de Europa; en España, dictó conferencias en el Ateneo de Madrid y en la Unión Ibero-Americana. A fines de año, Clorinda Matto volvió a Buenos Aires donde murió en 1909, no sin antes publicar su último libro Viaje de recreo.

\section{Escritora vanguardista y anticlerical}

A partir de la segunda mitad de la centuria, desde diversos sectores se fue llegando a un consenso sobre la necesidad de modernizar el país. Los ingentes recursos del guano entre las décadas de 1850 y 1860 permitieron una importante transformación material, especialmente limeña, y al mismo tiempo la constitución de una elite liberal, intelectual y política que, aunque heterogénea, reflexionó y promovió reformas dirigidas a convertir al Perú en una nación moderna. Es en esta época que se empieza a discutir lo inacabado del proyecto republicano, la ausencia de ciudadanía, la expansión y carácter de la escuela, la violencia política, y la relación del Estado y la Iglesia. Parte de las reformas modernizadoras se expresaron en la aprobación del Código Civil en 1852, la eliminación de los fueros eclesiástico y militar en la década de 1850, la abolición de la esclavitud y el tributo indígena en 1854 .

Sin embargo, a partir de la década de 1860, la modernización liberal encontró las resistencias de las elites políticas conservadoras y miembros del clero católico que coincidieron con la revitalización de un catolicismo militante y ultramontano que, desde el papado de Pio IX (1846-1878), empieza eclipsar ese liberalismo que había sido patrimonio de parte importante del clero desde las primeras décadas del Perú republicano. Las resistencias ante 
las Constitución de 1867 y las reformas educativas durante el gobierno de Manuel Pardo (1872-1876) fueron muestras elocuentes de este catolicismo conservador y militante. Los debates en torno a la posición de la Iglesia en la república dividieron ideológicamente a las elites políticas e intelectuales, mientras que los caudillos gobernantes asumieron posiciones pragmáticas alternando lealtades de los círculos civiles. Ello explica en parte el carácter tibio de las reformas liberales que se ralentizan al reducirse los ingresos guaneros y se detienen frente al descalabro en la guerra del Pacífico (Armas, 1998, pp. 83 y ss.; Mücke, 2010, pp. 70-71).

La posguerra fue un período propicio para la reflexión y elaboración de proyectos de reformas profundas que permitieran reconstruir del país. La crisis económica y el colapso del Estado se convirtieron en un catalizador para las elites intelectuales que buscaron enjuiciar los grandes problemas nacionales responsables de la derrota, así como su necesaria terapéutica. Con esto coincide el enriquecimiento y complejización del mundo intelectual producto del arribo de nuevas ideologías, como el positivismo, el darwinismo social y el anarquismo, y el fortalecimiento de espacios de sociabilidad letrados en los que se solidarizan afinidades intelectuales y políticas, y desde donde se discute y publican propuestas de modernización del país (Chocano, 2010, pp. 425-428; Denegri, 2004, pp. 119 y ss.). En este ambiente de efervescencia, se discutirán con mayor urgencia problemas como el carácter embrionario de la comunidad nacional y la concomitante civilización/occidentalización de la mayoritaria población indígena; la modernización material y el restablecimiento económico del país; la inmigración europea y la libertad de cultos; así como la pacificación de la vida política, condición necesaria para la construcción de ese futuro imaginado (Mc Evoy, 1999, pp. 271-277; Klarén, 2004, pp. 249-252; Huarag, 2013, pp. 32-33).

Es en este ambiente intelectual en el que se enmarca la actuación Clorinda Matto de Turner. Ella, como otros intelectuales de su generación, fue una convencida de la necesidad de modernizar el país, modernización que debía expresarse en la dimensión material, pero sobre todo en la vida social y cultural (Arango-Keeth, 2010, pp. 214-217). En sus obras, así como en las publicaciones periódicas que dirigió, abundan referencias de telégrafos, ferrocarriles, pilas de Volta, máquinas de coser, nuevos productos importados. En Los Andes Libres saludó reiteradamente la inventiva de los países industrializados 
y los felices resultados en el bienestar humano. ${ }^{2}$ Como lo demostró también en La Bolsa y en El Perú Ilustrado, creía en los beneficios que reportaría la introducción de maquinaria moderna, el emprendimiento de hombres de industria, así como en el papel importante y digno del trabajo manual (Miserés, 2009-2010, pp. 171-188). ${ }^{3}$ El progreso material debía ir acompañado por su contraparte social y cultural, en el sentido de transformar las viejas formas de vida social y alcanzar la civilización a ejemplo de los países occidentales.

Para la escritora, uno de los rasgos que distanciaba al Perú decimonónico de aquellos países lo constituía la ausencia de una comunidad nacional (Vargas, 2010, pp. 223-242). La guerra había mostrado — con sus pasajes dolorosos - qué tan necesario era construir la patria en un país en donde la mayoría de sus habitantes, la población indígena, no conocían el significado de ese nombre. ${ }^{4}$ Que los indígenas fueran considerados ciudadanos debía ser el resultado de la extensión de la educación, la palabra escrita para el conocimiento de la ley, y del reconocimiento de su dignidad y respeto de sus derechos por autoridades (civiles y eclesiásticas), justas y morales, que aplicaran la ley con rectitud y patriotismo. ${ }^{5}$ De similar manera, la modernización podía alcanzarse eliminando las barreras que inhibían el desarrollo de las mujeres, como madres en el espacio doméstico, pero también como sujetos presentes y útiles en el espacio público, cuya voz se expresaría por medio de la palabra escrita.

Entre las rémoras para el progreso social y cultural del país que identificó Matto se encontraba el conservadurismo de la Iglesia y la corrupción del clero peruano. A lo largo de su carrera intelectual, Clorinda desarrolló una posición crítica frente a la Iglesia católica y a las prácticas que consideraba retrogradas y especialmente venales. En sus primeras novelas, Aves sin nido e Índole, denunció su corrupción y falta de ilustración, su posición dentro de las redes de poder patriarcales, así como su connivencia en la explotación de la población indígena y en la subordinación de las mujeres. La primera, concebida como una novela de crítica social, denunció las prácticas de dominación sobre los indígenas del mundo rural, ejercidas por la tríada patriarcal del juez, el alcalde

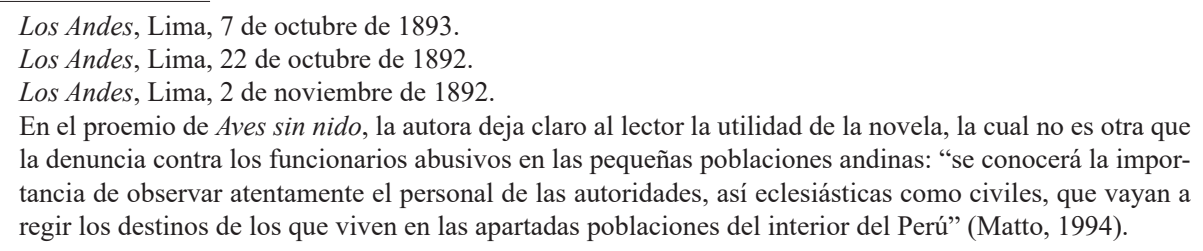
la denuncia contra los funcionarios abusivos en las pequeñas poblaciones andinas: "se conocerá la importancia de observar atentamente el personal de las autoridades, así eclesiásticas como civiles, que vayan a regir los destinos de los que viven en las apartadas poblaciones del interior del Perú" (Matto, 1994). 
y el cura, protagonista este último del ritual oral que fundaba el compadrazgo, insustituible para el funcionamiento del prebendalismo; era él quien resguardaba los intereses de los grupos de poder local y autorizaba las alianzas convenientes para la reproducción de la vida social. Mientras que en Índole retrata nuevamente a un sacerdote corrupto e inmoral que se aprovecha de su posición y el tradicionalismo de las feligresas para satisfacer sus apetitos sexuales. La novela fue sobre todo una crítica de su sociedad, especialmente de las costumbres tradicionales expresadas en el catolicismo conservador que inhibían y sometían la individualidad de las mujeres.

Las novelas de Clorinda no se encuentran en el vacío, eran parte de las críticas y apuestas compartidas por liberales, positivistas, librepensadores, masones y anarquistas que asociaban lo católico a lo conservador y promovieron una relación secular entre el Estado y la Iglesia (Klaiber, 1995, cap. II, III). Ante tales embates se produjo una contraofensiva de la Iglesia peruana luego de estar en franco repliegue frente a las reformas secularizadoras, tibias pero progresivas, como la eliminación de los fueros eclesiásticos, de los diezmos y la desamortización de tierras. Su posición en la sociedad, cuestionada sí en algunos sectores de las elites y grupos profesionales mesocráticos, era aún lo suficientemente fuerte como para responder a la crítica social y los proyectos modernizadores; debe recordarse su papel importante en el registro de los actos vitales, como nacimientos, matrimonios y defunciones, los cuales tenía fuerza legal hasta el siglo XX (Velásquez, 2015, pp. 448-460), así como en los rituales y festividades que regulaban, cohesionaban y distendían la vida de la mayoría de la población peruana, en todos los niveles sociales.

Las respuestas del clero peruano no se hicieron esperar. Al poco tiempo de la publicación de Aves sin nido, el sacerdote y presidente de la Unión Católica del Cusco Fernando Pacheco se encargó de subrayar dos piezas del poder eclesial en las que la Iglesia se había sentido particularmente ofendida: el ministerio parroquial y el celibato. En su pronunciamiento, Pacheco acusó el "espíritu anticatólico" de la "infernal" obra, la cual era "semilla de la guerra contra Cristo y su Iglesia, contra sus dogmas y sus instituciones." (Ferreira, 2005, p. 32). Las relaciones ya tensas de Matto con el clero católico subieron de tono en agosto de 1890 con la publicación en El Perú Ilustrado de "Magdala", un artículo del escritor Enrique Maximiliano Coelho Netto, en el que se sugería la atracción sexual de Cristo por María Magdalena (Portugal, 1999). Ello causó escándalo en Lima y diversas ciudades del país, como Cusco, Puno y en especial en Arequipa. La furia eclesial y conservadora no 
se limitó a presionar y lograr la prohibición de la circulación de la revista, adicionalmente se hicieron movilizaciones y pronunciamientos en contra de la escritora. Su efigie fue quemada públicamente en Arequipa y Cusco, y en esta última ciudad se publicó un pronunciamiento firmado por mujeres católicas en el que denostaron contra la autora, considerándola blasfema (Ferreira, 2005, pp. 32-33).

Aunque la publicación del artículo de marras no recibió la autorización de la escritora, este revuelo llevó a su excomunión y la inclusión de Aves sin nido en la lista de los libros prohibidos por la Iglesia católica. Las presiones de esta y de los sectores conservadores - se prohibió bajo pena de pecado mortal la lectura y difusión de El Perú Ilustrado - llevaron a su renuncia de la dirección y a la promesa personal del propietario, Pedro Bacigalupi, de vigilar su contenido para que se levantase la censura eclesial. El motivo de fondo era sin duda una represalia a la publicación de Aves sin nido (Berg, 1997). Conviene no olvidar que esta furiosa reacción no era un hecho aislado, sino parte de un ambiente de intolerancia y de conservadurismo, como lo muestra el caso del italiano Francisco G. Penzotti y de otros misioneros metodistas, quienes fueron arrestados en Arequipa y en el Callao acusados de difundir libros inmorales y corruptores y propagar ideas heréticas; en realidad habían llegado al Perú en 1888 como representantes de la American Bible Society de Nueva York para vender sus biblias (Armas, 1998, p. 153).

\section{Educación y escritura femenina}

La preocupación por la educación de las mujeres atravesó la obra de Matto de principio a fin. Cuando dirigió en Arequipa La Bolsa en 1883, inauguró una columna, "Los lunes", que registró noticias y reflexiones sobre la educación en general y la de las mujeres en particular; allí buscó dar "preferente atención a la educación de la mujer base fundamental del progreso de las sociedades y de la felicidad de las familias". ${ }^{6}$ En El Perú Ilustrado también escribió de modo sostenido sobre el tema en cuestión. En estas publicaciones animó a escritoras y escritores a elaborar sus opiniones sobre la educación. El optimismo de Clorinda Matto respondía al reconocimiento de la capacidad moral e intelectual femenina, actitud bastante poco usual durante el siglo XIX en

6 La Bolsa, Arequipa, 3 de agosto de 1883; El Perú Ilustrado, Lima, 20 de setiembre de 1890. 
que la mayoría, incluida la vanguardia, pensaba que el super-yo femenino era prácticamente inexistente. Esta apuesta no le impedía ver la desidia de la que necesitaban emanciparse sus congéneres, la misma que las mantenía ajenas a los sueños del progreso (Mannarelli, 2013, p. XX).

En el ambiente intelectual marcado por la regeneración de la nación propio de la posguerra, Clorinda y la mayor parte de las mujeres escritoras, periodistas y maestras fueron optimistas, aunque no complacientes. Más bien vieron cosas que otros preferían soslayar, como el acceso de las mujeres a una educación diferente. Esto no solo las llevó a redefinir la casa y a investir al “ángel del hogar" de un significado innovador, sino, en algunos casos, inclusive a catapultar a las mujeres al mundo público y al cuestionamiento de las formas de ejercicio de la autoridad. Matto concibió la casa como un microcosmos donde había que ingresar para crear la patria. Los deberes privados y los sociales estaban articulados de modo estrecho. Buenos padres eran buenos ciudadanos, buenas madres también. No obstante, los hombres hacían las leyes, las mujeres las costumbres. ${ }^{7}$

Pero Matto no compartía del todo la dicotomía burguesa que identificó lo racional, el conocimiento, la ciencia con lo masculino, y lo femenino con las emociones y la naturaleza. Ella reconocía una naturaleza femenina, pero no la circunscribía de modo indefectible al hogar, pues creía que las mujeres podían acceder al espacio público por medio del trabajo: "La profesión de la mujer lejos de encerrar un inconveniente para el matrimonio, significa una facilidad para la ventura de los esposos". ${ }^{8}$ La casa podía ser el recinto de las mujeres, sin embargo, Matto advertía: "Acordémonos de aquellas infelices mujeres, hostigadas en los misterios del hogar por los celos infundados; gastadas por la glotonería de los maridos; reducidas a tomar aire débil y tomar aliento escaso, y al punto tendremos a la vista la infeliz mujer displicente, pálida, ojerosa, en cuya mente cruzan pensamientos siempre tristes, y cuya voluntad de acción duerme el letárgico sueño del desmayo" (en Küppers, 1989, p. 232). Y aunque Matto afirmó que la función primigenia de las mujeres era la maternidad, fue una dura crítica de la forma en que estas se sometían a ese mandato de la naturaleza que reconocía como tal, pues los espíritus inferiores y egoístas quieren "circunscribir la esfera de acción de la mujer al estrechísimo recinto del elemento puramente reproductor, de simple placer o de utilidad servil. Seres ennoblecidos por la idea de la igualdad y del derecho, han juzgado y

$7 \quad$ La Bolsa, Arequipa, 28 de mayo de 1885.

8 El Perú Ilustrado, Lima, 20 de setiembre de 1890. 
juzgan con verdadero criterio en lo justo a la mujer inteligente" (Matto, 1902, p. 123).

Matto no desconoció la importancia de la escolaridad. A lo largo de su obra las referencias a la escuela también son explícitas, por ejemplo, en Aves sin nido afirmaba que "[d]onde la carencia de escuelas, la falta de buena fe en los párrocos y la depravación manifiesta de los pocos que comercian con la ignorancia y la consiguiente sumisión de las masas, alejan, cada día más, aquellos pueblos de la verdadera civilización" (Matto, 1994, pp. 36-37, 234). Sin embargo, sus opiniones en favor de ella se orientaron sobre todo a propósito de su significado, tanto para la nación como para las mujeres mismas. Se ubicó así entre las que pensaron en la educación no solo como un medio para organizar la nación, sino como un fin en sí mismo que las mujeres tenían derecho a perseguir para su propio provecho.

En sus novelas, tanto en Aves sin nido (1889) como en Índole (1891) y en Herencia (1895), los personajes femeninos están definidos en función de sus vínculos con la educación y la palabra escrita; es decir, la instrucción es un referente sustantivo en su configuración. Lo vulnerable de las mujeres indígenas se explica por estar alejadas de las aulas y de la palabra escrita, mientras que las criollas instruidas se portan como madres juiciosas y atinadas consejeras. La educación configura las identidades que encarnan el progreso, la felicidad y está lejos de aquellos que representan la barbarie, la decadencia, el sufrimiento (Mannarelli, 2013, pp. 25-29). El corazón de una mujer era todavía un abismo oscuro mantenido por la ignorancia (Matto, 1994, pp. 142-143). La falta de educación en las mujeres incitaba el dominio masculino: "Y esta índole prevalece con mayor fuerza en la mujer, descuidada en su educación por el egoísmo masculino, y entregada a sus propias fuerzas, en esta tramoya de la vida cuyos cuadros dispone el varón." (Matto, 1974, p. 189).

Consecuentemente, Clorinda intervino en la controversia sobre el matrimonio por conveniencia y lo definía como "unión monstruo cuando no existe el amor" (Matto, 2016[1895], p. 170). Rechazó el arreglo conyugal no solo porque inhibía la opción amorosa, sino porque el mandato eclesiástico de reproducir la especie atentaba contra la salud de las mujeres y sus posibilidades vitales. En la autora encontramos una relación original entre la educación femenina y el control de la natalidad; aquella se convierte, a su vez, en un referente para el control del instinto sexual masculino (Mannarelli, 2013, pp. 25-29). De este modo, la educación de las mujeres cuestionaría sendos pilares del poder doméstico y clerical. 
La educación para Matto no se desliga de la grandeza de la patria y de su dignidad. Igual que Teresa González de Fanning, ve en la difusión de la escuela un modo en el que los heterogéneos ingredientes que hacían el Perú podían convivir en armonía. Si bien las vanguardistas no estuvieron del todo familiarizadas con la idea de la igualdad, sí con la utopía de la justicia, donde la educación fue uno de sus ejes. En 1891, a raíz de un comentario sobre los Estados Unidos, aparece en El Perú Ilustrado el término igualdad empleado por Matto para calificar a ese país como el que más oportunidades ofrecía a las mujeres de librarse del tutelaje de la ignorancia, lugar en el que podían alcanzar "el emporio de su personalidad, llamada á brillar con todos los resplandores de la ciencia allá donde no se oprime la voluntad ni se esteriliza la fuerza creadora del cerebro". ${ }^{9}$

El espectro que dibuja el interés de Matto por la educación femenina va desde la formación escolar hasta las aspiraciones políticas, como ella misma protagonizó algunos años después. En relación a lo primero, publicó Elementos de literatura según el Reglamento de Instrucción Pública para el uso del bello sexo en 1884. Tenía en mente la idea de lo que podía ser una ciudadana capaz y confiaba en el poder de la escritura para transformar a las personas. Por eso incluyó en Elementos modelos femeninos como Teresa de Ávila, Madame Staël y Cecilia Bohl, todas vinculadas a la autonomía intelectual, espiritual y material que puede implicar la pluma, la tinta y el papel.

Las reflexiones de Matto sobre la educación de las mujeres no se desligaron de los atributos que le confirió a la palabra escrita en general y a la que estuvo en manos de las mujeres en particular, que produjo muchas e intensas tensiones. Hombres y mujeres percibieron sus efectos en el cuestionar el orden social. Mujeres como María Mendiburu de Palacios expresaron el recelo que producía tal recurso: "Las escritoras y artistas pueden hacer mucho bien y encantar a la sociedad, pero esas son notabilidades a quienes el genio arrastra y saca de su centro; y si llegan a ser madres de familia por fuerza tendrán que limitarse a eso". ${ }^{10}$ Ante tal nerviosismo, la mirada de Matto se fijaba en otra cosa: " $[\mathrm{H}]$ agamos escritores nacionales $[\ldots]$ siendo el periódico el laboratorio donde se levante la columna de fósforo elaborado en el cerebro para alumbrar el mundo y desterrar las tinieblas de la ignorancia. Es deber nuestro utilizar las horas bonancibles de la paz. Hagamos de las hojas impresas, perfumadas hojas otoñales que volando como aristas al hogar y al taller, lleven no solo luz

$9 \quad$ El Perú Ilustrado, Lima, 11 de julio de 1891.

10 El Correo del Perú, vol. 2, número extraordinario, 31-12-1873, p. XII. El subrayado es mío. 
y aroma, sino el bienestar consiguiente al trabajo remunerado". ${ }^{11}$ Esta incursión, sin duda, despertó gran controversia.

Merece atención una idea de Matto acerca de cómo la educación llevaba a renunciar a los intereses particulares (Mannarelli, 2013, pp. 25-29). Según la autora, la educación estaba ligada a la cultura pública y a su exigencia de posponer aspiraciones reñidas con el bien común. ${ }^{12}$ La educación era un complemento del periodismo que higienizaba la vida pública vigorizando la moral cívica (Ortiz, 2007, pp. 391-392). Matto era consciente de que promover la educación de las mujeres apuntaba a ensanchar el espacio público con nuevas voces, y que estas incomodarían a los patriarcas acostumbrados a monopolizarlo. Lo publicado por Matto en 1890 sobre Ana Mac Sorley en El Perú Ilustrado revela su opinión y lo que ocurría en la época: "Aplaudimos la constancia de la señorita viuda de Mac Sorley, felicitándola por haber coronado con brillo su carrera, pero también, le damos la voz de cuidado. Entre nosotros, la mujer que sobresale, es como la oropéndula de vistoso plumaje: todos los moscones van a picarla, todas las miradas devoran su belleza, y muy pocos, perdona el grave delito de "no ser nada", 13 "a la mujer ilustrada los tontos le tienen miedo" (en Küppers, 1989, p. 197).

La educación de las mujeres se oponía pues a la censura y a la intolerancia, y ella lo sabía bien a raíz de la publicación de Aves sin nido: "Si no atendemos a la ilustración de la mujer, cuanto hagamos en pro de los adelantos modernos será sin éxito y los que creíamos sólidos edificios, serán débiles castillos de naipes. [...] instruyamos a la mujer y más tarde no se quemarán nuestros libros, ni nuestros sacerdotes nos anatemizarán, pues irán finados por la ciencia y la caridad". ${ }^{14}$ La tolerancia pública, la secularización y la educación femenina eran para Matto aspectos del mismo camino hacia la modernidad, derrotero que no excluía necesariamente la instrucción religiosa, aunque esta debía ser ejercida en base a un cristianismo austero y humano inspirado en "el gran libro de la humanidad" que contenía el código moral más puro predicado por Jesús el Nazareno. ${ }^{15}$

11 El Perú Ilustrado, Lima, 5 de octubre de 1889.

12 El Perú Ilustrado, Lima, 27 de junio de 1891.

13 El Perú Ilustrado, Lima, 20 de setiembre de 1890.

14 El Perú Ilustrado, Lima, 1 de noviembre de 1890.

15 La Bolsa, Arequipa, 20 de octubre de 1885. 


\section{Entre el periodismo y la acción política: "salir a la calle en aguacero"}

Firme en sus convicciones, y probablemente bajo la experiencia de su salida forzosa de El Perú Ilustrado, Clorinda abrió con su hermano David la imprenta La Equitativa. El establecimiento contaba con una imprenta a vapor Marinoni, de la cual mencionaban era la "única importada á la capital y la más moderna por su mecanismo". El negocio, ubicado a pocas cuadras de Palacio de Gobierno (en la calle Ancash, luego se mudarían a la calle Lártiga), estaba abierto a la publicación de libros, periódicos, tarjetas u otras a "[p]recios sin competencia". ${ }^{16}$ Entre otras cosas, su fundadora podía afirmar orgullosamente que era "La Equitativa, servida por señoras, fundada en febrero de 1892 por Clorinda Matto de Turner". ${ }^{17}$ En sus prensas se publicaron obras literarias y académicas, propias como Hima-Sumac, Leyendas y Recortes y Herencia, así como de otros autores, como La historia del Perú del inglés Clement Markham.

Este proyecto editorial formaba parte de su visión de modernidad en el Perú; confiaba en la capacidad regeneradora de la palabra escrita, expresada a través del libro, la lectura y el periodismo. En un país, donde la mayoría de la población era quechua y aimara hablante, correspondía a la palabra escrita vehiculizada por la imprenta liberarlos y civilizarlos. Respecto a "nuestros desgraciados hermanos" indios proponía "buscar en adelante la manera de rehabilitarl[os] si queremos ufanarnos de ser cristianos y civilizados", enseñándoles que "desde el prodigio de Gutenberg, no sólo sirve el plomo para hacer balas que destruyen y esclavizan, si que también para fundir tipos que engrandece á las sociedades y que subliman al hombre hasta el punto de hacerle tocar con la frente el cielo". ${ }^{18}$ Tarea esta que, como en el caso de las mujeres, pasaba necesariamente por la escolarización y alfabetización, pues no es posible que "quer[a]mos periódico y libro antes que maestros y escuela, sin que nos importe nada el arrojar uno y otro entre personas que no conocen el alfabeto ni entienden el idioma en que les hablamos". ${ }^{19}$

Respecto de la prensa, la escritora consideraba que era una de las "quintaescencias" de los logros humanos en los que se mezclaba las artes (la escritura) y las ciencias (la imprenta moderna). El periódico, esa "hoja de papel preparada con la velocidad de las máquinas modernas", debía ser un instru-

16 Los Andes, Lima, 5 de octubre de 1892.

17 Muestrario de la imprenta «La Equitativa», servida por señoras, fundada en febrero de 1892 por Clorinda Matto de Turner (Lima: La Equitativa, 1892).

18 Los Andes, Lima, 2 de noviembre de 1892

19 Los Andes, Lima, 28 de setiembre de 1892. 
mento para la "misma vertiginosa proporción de la propaganda educacionista" que debía emplear el "educador popular ó sea [el] periodista" para la civilización de los pueblos y la mejora de la sociedad en su conjunto. ${ }^{20}$ Para ella, el periodista era quien:

gota á gota hace caer en la conciencia de los mandatarios y en la del pueblo las ideas, más que nadie debe insistir en sus nobles propósitos. Apóstol de la civilización, soldado de Dios que combate por la verdad, jamás debe ceder por las contrariedades, ante los obstáculos con que tropieza. Sólo así se mostrará digno de la causa santa á que consagra su cerebro. ${ }^{21}$

Bajo estos principios, Matto fundó el periódico Los Andes, publicación que se imprimió en los talleres de La Equitativa desde octubre de 1892 hasta marzo de $1895 \mathrm{y}$, como afirmaba su directora, estaba "destinado a provincias donde ha tenido una acogida admirablemente satisfactoria". ${ }^{22}$ Su publicación, sin embargo, también mostró un claro viraje en la participación de la escritora en el espacio público. En Los Andes, además de los contenidos culturales, artísticos o literarios que usualmente formaban parte del repertorio de su pluma, Clorinda destinó gran parte de sus editoriales a defender las administraciones del Partido Constitucional y la figura de su caudillo y fundador, Andrés Andrés Cáceres, de quien esperaba su retorno a la presidencia en $1894 .{ }^{23}$ Hasta 1892 , su participación respondía principalmente a un imperativo moral cívico, en el sentido de que sus intervenciones en prensa y por medio de la novela se sostenían en la responsabilidad de los intelectuales en propender al bien del país. Esto se observa con toda claridad en la denuncia social de sus novelas, pero también se hace manifiesta sus esporádicas declaraciones sobre la situación política del país, como en la semblanza dedicada a Cáceres, donde afirmaba que no fue mi “ánimo escribir el JUICIO POLÍTICO de la administración del General”, sino más bien "la idea de la rectitud de miras y lo levantado de aspiraciones que nace del estudio moral seguido en el personaje que me ocupa" (Matto, 1890, p. 191).

20 Los Andes, Lima, 18 de octubre de 1893.

21 Los Andes, Lima, 5 de noviembre de 1892.

22 Así lo confirmaba el corresponsal de Cusco, en donde "se han colocado todos los números y hoy pedimos á la administración algunas colecciones más”. Los Andes, Lima, 22 de octubre de 1892.

23 Andrés Avelino Cáceres fue un destacado militar decimonónico que se consagró como héroe nacional por liderar la resistencia peruana a la ocupación chilena durante la guerra del Pacífico. Su valor y talento militar le valieron el beneplácito nacional, convirtiéndose en presidente constitucional en 1886, con el amparo del Partido Constitucional, organización compuesta de los jefes militares que lo acompañaron en la Campaña de la Breña. Al culminar su mandato, logró la elección de su correligionario constitucional y compañero de armas, Remigio Morales Bermúdez, quien debía devolver el favor a Cáceres en 1894. 
Su participación política desde la prensa en favor de un caudillo, fue leída inmediatamente por sus críticos como una incongruencia moral, pues, en sus primeros años de escritora, había sido crítica del carácter orgiástico de la prensa, su espíritu de libelo, así como sus dependencias y ataduras con los grupos de poder. ${ }^{24}$ Este rechazo se observa desde las páginas de El Recreo, donde reclamó por una prensa diferente que fuera más allá de las mezquindades propias del talante clientelar: "Siempre hemos tenido publicaciones en el país; pero todas y en casi todo tiempo no han perseguido más fin ni tenido otro carácter que el político, mientras que los verdaderos intereses sociales han sido descuidados, faltándoles un órgano que abogue de continuo por ellos". ${ }^{25}$ Sin embargo, este viraje puede entenderse como el correlato de sus aspiraciones de transformación del país. Matto era consciente de que sus propuestas modernizadoras no podían realizarse solo en el plano del debate de la opinión pública y que para hacerlas efectivas era necesario la política.

No obstante, la política decimonónica era un mundo masculino marcado por el liderazgo de caudillos, militares y civiles, quienes articulaban redes en competencia por el control de los espacios locales, regionales y el Estado central. Era un mundo de patriarcas, basado en alianzas clientelares, parentescos e incipientes partidos políticos que excluía formalmente y de hecho a las mujeres de las decisiones públicas y las confinaba al espacio doméstico. Clorinda lo sabía muy bien; ya en el año 1882 no había trepidado en escribir, en plena guerra con Chile, al entonces presidente Lizardo Montero para "recordarle el ofrecimiento me hizo como caballero, respecto á la Diputación de esta provincia en favor de mi hermano Daniel", pedido en el que empleaba las propias lógicas del honor masculino, pues "no puedo poner en duda las palabras de usted". ${ }^{26}$ Su pertenencia a una familia acomodada y cultivada le permite actuar entre los hombres poderosos y emplear la clave del parentesco para influir en las decisiones políticas.

Es precisamente en medio del descalabro de la guerra donde Matto desarrolla una identidad política que la acompañará en su etapa de madurez

24 Salvo algunas excepciones, la prensa peruana decimonónica tenía un cariz fuertemente político, la mayoría era de vida efímera que dependía de la popularidad del caudillo o del círculo político al que respaldaban. De acuerdo con Carlos Forment (2012, pp. 133, 223)., en total, desde la proclamación de la Independencia hasta 1875 , se publicaron 571 periódicos, a veces a un ritmo promedio de 25 periódicos por año. La mayoría era de vida breve, no superando el año de circulación.

25 El Recreo, 1 de febrero de 1876.

26 "Carta de Clorinda Matto de Thurner al Señor Presidente Contra Almirante D. Lizardo Montero". Tinta, 11 de setiembre de 1882. Archivo personal de Luis Guzmán Palomino, a quien agradecemos nos haya permitido su consulta. Las cursivas son nuestras. 
y que la vinculó estrechamente a Andrés Avelino Cáceres y a los jefes de la campaña de la Breña. Su admiración por este hombre de armas fue explícita en las diversas biografías y semblanzas que escribió en las páginas de El Perú Ilustrado, Los Andes y en otros escritos que dedicó a reflexionar sobre la vida política del país. En su primera biografía, escrita aún al calor de la guerra civil de 1884, la escritora afirmaba que "[f]irme en sus convicciones, como lo admiramos; guiado por su amor a esta patria tan infortunada, Cáceres luchó contra toda clase de elementos encontrados para reorganizar el ejército defensor de nuestra integridad, y obtuvo, para el suelo donde nació, días de gloria". ${ }^{27}$ Esta afinidad para con el breñero no era un secreto en la época, pues la misma Matto confesaba al escritor Ricardo Palma, en enero de 1893, la filiación política de su publicación: "Como usted comprenderá Los Andes sirve al partido de Cáceres al que yo y mi familia hemos estado afiliados desde 1882". ${ }^{28}$

Estas palabras suyas expresaban su convicción: Cáceres era el político que más le convenía al país. De acuerdo con Matto de Turner, Cáceres era un rara avis en la política nacional, plagada de hombres que buscaban el beneficio propio en desmedro de los grandes intereses de la patria. Por ejemplo, al referirse a los trabajos eleccionarios de la oposición de las agrupaciones civiles —el Círculo Parlamentario de Mariano Nicolás Valcárcel y el Partido Civilista-, los describía como políticos ambiciosos movidos por las dietas y las intrigas parlamentarias o los negocios que podían arrancarle al Ejecutivo. ${ }^{29}$ Respecto de ellos podía sentenciar la directora de Los Andes: "[n]inguno que no ha prestado servicios al pueblo puede aspirar á guiar ese pueblo que lo desconoce por su acción". A diferencia de ellos, Cáceres era el ejemplo del patriotismo, es decir, de la acción desinteresada por el bien común: había hecho "fortuna á costa de su sangre y [...] como certificado de esos servicios prestados al país, p[odía] enseñar las cicatrices de su cuerpo en la defensa nacional"; por ello, "será siempre el caudillo de los pueblos del Perú que pronuncian con entuciasmo [sic]". ${ }^{30}$ En defensa de su candidatura y en repuesta a los afanes de los grupos políticos civiles (los hombres de Valcárcel y los partidos Civil y Demócrata) que ambicionaban suceder al Partido Constitucional en 1894, Clorinda no dudó en presentar argumentos pragmáticos que patrocinaban el militarismo, esto es, el gobierno

27 Esta biografía, aunque escrita en 1884, solo fue publicada en 1886 a propósito de la ascensión de Cáceres como presidente de la República. Clorinda Matto publica una biografía de Andrés Avelino Cáceres, escrita en 1884, en su libro Bocetos al lápiz de Americanos Célebres (pp. 175-192).

28 Citada en Arango-Keeth, 2016, p. 196.

29 Los Andes, Lima, 1 de octubre de 1892.

30 Los Andes, Lima, 7 de octubre de 1893. 
del país por los jefes militares, únicos hombres que —a su juicio- habían dado lustre a la historia del Perú y que simbolizaban el principio de autoridad:

Hoy, con igual precipitación, con el delirio que producen las frases retóricas en nuestra sangre inflamable, abogamos por el gobierno civil y la destrucción del militarismo. Para qué? Para salir tristemente decepcionados [...]. Aprendamos primero á mandar y á obedecer, y entonces, tal vez podremos despreciar, ingratos, el acero que cortó las cadenas, y que nos reunió para decir con la palabra de San Martín. Desde este momento el Perú es libre é independiente por la voluntad de Dios. Entonces, tal vez nos perdonen la ingratitud con que olvidamos que la palabrería civil perdió jirones de la Patria, y que si algo fulgura en el campo de humo, es el brillo de la espada de Bolognesi y la de Grau y la de tantos que supieron morir, porque sabían mandar y obedecer. ${ }^{31}$

Clorinda reconocía los logros de Cáceres y el Partido Constitucional en el período de la posguerra, entre los cuales destacaba la estabilidad política y la ausencia de guerras civiles en un siglo en el que, salvo períodos excepcionales de quietud, había sido una seguidilla de Gobiernos nacidos de golpes de Estado o guerras civiles, provistos de una autoridad siempre cuestionada por sus pares militares y su corte de hombres vestidos de frac. El Partido Constitucional había sido el único que había establecido "entre nosotros el imperio de la ley" luego de la guerra del Pacífico y la guerra civil posterior y, por tanto, Cáceres como su adalid era "el llamado á consolidar su propia obra - la era de paz y de trabajo de que disfrutamos - para que el Perú del porvenir sea grande y sus destinos envidiables. ${ }^{\prime 32} \mathrm{El}$ orden era indispensable para el progreso del país.

Desde la palabra escrita, Matto podía contribuir a construir el futuro imaginado en sus novelas y otros escritos, esta vez como aliada de un hombre fuerte que, además de garantizar el orden, había sido y era la expresión máxima de patriotismo. Desde las páginas de Los Andes afirmaba que "[s]i nuestra modesta pluma se ha puesto hoy á la causa que personifica el señor general Cáceres, es porque no podremos relegar al olvido que, fue él el que, de manera infatigable, hizo flamear gloriosamente nuestra enseña nacional aún en aquellos días de maldición que nos deparó un destino cruel”. Su convicción en la defensa del general se justificada en una moral cívica inspirada en virtudes también patrióticas que le imponía una responsabilidad como escritora y periodista que - como hemos mencionado - la había llevado antes a enjuiciar los problemas del país. Ella misma afirmaba que debía cumplir "los debe-

31 Los Andes, Lima, 1 de octubre de 1892.

32 Los Andes, Lima, 26 de octubre de 1892. 
res austeros que nos impone nuestro ministerio" que los cumpliría "siempre, como patriotas y como honrados, sin que pueda haber consideración alguna que nos desvíe, ni por un instante, de la línea inflexiblemente recta que hemos adoptado [pues] no tenemos más bandera política que el bicolor bendito". Desde su tribuna conminaba al resto de partidos políticos que arriaran sus banderas y se plegaran a la "causa de la Patria personificada por la constitucionalidad que tiene su jefe único [Cáceres]". ${ }^{33}$

La audacia política de la escritora no pasó desapercibida, ni dejó de tener detractores entre sus amigos y enemigos públicos. Algunas personalidades cercanas suyas, como el mismo Palma, intentaron disuadirla: "Mucho aconsejé a mi queridísima comadre Clorinda que no se mezclara en política". ${ }^{34}$ También escritores y periodistas competidores suyos, así como opositores del Partido Constitucional, lanzaron durísimas críticas contra la escritora. Como ha documentado Juan José Pacheco, en las páginas de la prensa de oposición se le enrostró su filiación política y el patrocinio pecuniario del cacerismo; se hizo sorna de su origen cusqueño y su vocación en favor de los indígenas, refiriéndose a ella como Clorenda o Clor-india; ${ }^{35}$ pero sobre todo se le criticó por su carácter de mujer que empleaba un atributo masculino como era la palabra escrita para participar en la ida pública y política. Fue sin duda Pedro Paz-Soldán y Unanue, Juan de Arona, quien atacó más vehementemente a Clorinda por su condición de mujer escritora: "Te has metido a marimacho con los hombres en refriega, ya te daran un cocacho, no lo ves porque eres ciega y zarca como mi macho. [...] dejate de nidos y aves, pues ni ortografia sabes. Mi plata, vieja jamona. A costa de mis dineros publicas hojas inmundas." 36 Aún más, respecto de La Equitativa, Paz-Soldán ironizó el estatus de señoras con el que Matto buscó dignificar a las trabajadoras de su imprenta:

La Equitativa. / Con este nombre se ha abierto un nuevo establecimiento tipográfico [...] el nuevo plantel de rechinar va á ser servido por.... Señoras. / Instintivamente hemos echado mano al frac y los guantes, lo que va á ser un embarazo para los marchantes que carezcan de estos adminículos, ó que no estén de humor de ponérselos al ir á contratar una impresión. / Las otras imprentas se llamarán ahora, lógicamente servidas por señores. / Lo que va á desterrar de los talleres los géneros hombre y mujer. [...] Admitiendo que todas las actuales ó fu-

33 Los Andes, Lima, 26 de octubre de 1892.

34 Carta de Ricardo Palma a Lola Rodríguez de Tió. Lima, 15 de octubre de 1895 (Palma, 2005, p. 208).

35 El Leguito Fray José, 19 de mayo de 1893; La Cachiporra, 15 de diciembre de 1892 (en Pacheco, 2018, pp. 138-141).

36 El Chispazo, Lima, 22 de abril de 1892 (en Denegri, 1996, p. 176). 
turas tipógrafas de La Equitativa sean todo lo señoras que se quiera, una vez que entran á cajistas, deben guardarse para cuando vuelvan á su casa un tratamiento que, en el taller, produce el mismo mal efecto que en el mom épouse de los porteros de Paris, en donde la gente más encopetada dice ma femme. ${ }^{37}$

La escritora se explicaba estos vituperios como producto de los apasionamientos personales y políticos de lo que llamaba "prensa naciente". ${ }^{38}$ Algunos periodistas, movidos por la envidia, eran "[p]rontos para la crítica" y no reconocían en sus pares — como le sucedía a ella misma - los méritos de sus colegas, pues parecía que "la agena gloria nos hiciera sombra cuando en verdad es una antorcha más en el camino de la luz". 39 Pero peores aún eran los periodistas y escritores que, bajo intereses personales, defendían a lo largo de su carrera diversas causas, sin un verdadero compromiso con un ideario o un caudillo que lo representase; los tildó de "tránsfugas del pensamiento y del sacerdocio de esta sublime religión del siglo XIX que se llama la Religión de la propaganda escrita". Eran estos, para ella, su total opuesto. Su comportamiento resultaba más dañino si se consideraba que estos malos ejemplos promovían la desmoralización de los ciudadanos, de allí que "[e]l nivel moral de los pueblos se refleja en la cultura de su prensa y en los prestigios de sus escritores". 40

Clorinda Matto fue consciente del costo que conllevaba su apuesta, pero aceptó el reto de ser una de las pocas mujeres de fines de siglo XIX — como así lo hizo Mercedes Cabello en su novela El Conspirador-que se atrevieron a escribir públicamente sobre política. En la carta dirigida a Palma ya referida, afirmaba que "[c]uando fundé el periódico, compadre, hice de cuenta que salía a la calle en aguacero y que era inevitable el mojarse mucho menos acá donde los paraguas no se usan" (en Arango-Keeth, 2016, p. 196). Sus críticas a los posibles contendientes del general Cáceres le valieron prevenciones y molestias, especialmente cuando responsabilizó al otrora poderoso Partido Civil, compuesto de la plutocracia limeña, de la guerra infausta: "Ya me han dicho zamba canuta porque dije, que la ruina del país se debía a don Manuel Pardo, a esa secreta alianza con Bolivia y que la miseria de hoy era el legado del partido de los negros recuerdos. Sigo adelante sin levantar moño. Ya los venceré con la constancia, con la verdad y con el patriotismo" (en ArangoKeeth, 2016, p. 196).

37 El Chispazo, Lima, 12 de marzo de 1893 (en Pacheco, 2018, pp. 142-143).

38 Los Andes, Lima, 18 de octubre de 1893.

39 Los Andes, Lima, 5 de noviembre de 1892.

40 Los Andes, Lima, 18 de octubre de 1893. 
La actividad política de Clorinda se sostuvo hasta el final de las administraciones del cacerismo, pese a que este partido se había desgastado ostensiblemente luego de ocho años de gobierno (1886-1894). Nicolás de Piérola, líder del Partido Demócrata y el opositor con mayores oportunidades para disputar la presidencia, se encontraba exiliado luego de escapar de la cárcel en 1890 al habérsele abierto un juicio militar por sus actos durante su dictadura en plena guerra con Chile, entre ellas acusaciones de corrupción, mientras que su órgano de prensa El País había sido clausurado ese mismo año, lo mismo que La Tunda. El Círculo Parlamentario y el Partido Civil, habiendo colaborado en momentos distintos con los constitucionales, acrisolaban su oposición luego de ver la nula posibilidad de alternancia al hacerse manifiesta la candidatura de Cáceres sostenida por el Partido Constitucional. Mientras la fecha de las elecciones se acercaba, se hacía más evidente el apoyo de la alta oficialidad del Ejército y la Marina, la Guardia Civil y la Gendarmería, en favor de la continuidad de este partido. La muerte repentina del presidente Morales Bermúdez en abril de 1894 y su reemplazo por el segundo vicepresidente y jefe cacerista, Justiniano Borgoño - en vez del primer vicepresidente, el civil Pedro Alejandrino del Solar- generó un ambiente de sospecha que inhibió a los partidos políticos de participar en las elecciones de ese año. Elegido Cáceres como candidato único, solo era cuestión de tiempo para que se observara una fuerte movilización armada de la coalición de los partidos civiles que derivó en una guerra civil que concluyó con la victoria militar y luego electoral de Nicolás de Piérola.

\section{Reflexiones en torno a la destrucción de La Equitativa}

La pax cacerista había llegado a su fin, y las glorias de los "breñeros" como eran llamados los partidarios de Cáceres se habían ido apagando. Las antiguas lealtades, por lo menos buena parte de ellas, habían dejado de ser tales; para muchos de sus aliados civilistas el régimen constitucionalista había abandonado sus iniciales arrestos (Mc Evoy, 1997). Las rivalidades entre los patriarcas provincianos y la administración militarizada fiel al gobernante en la mayoría de regiones alcanzaban su zenit. En su corto mandato, en medio ya de una economía deprimida, Cáceres tomó medidas impopulares para reprimir la oposición armada que afectaron a diversos grupos sociales: incrementó el número de fuerzas del orden, creó nuevos impuestos y subió los existentes, 
desplegó en Lima espías y prohibió a la prensa capitalina dar información sobre los sucesos de los movimientos en su contra, so pena de multa como sucedió con El Callao y El Comercio; los guardias de policía parados en la puerta del diario, impidieron la circulación de una edición de este último (Basadre, 1969, t. X, pp. 101-102, 106-107). Por el contrario, desde las tribunas caceristas - entre los que se encontraban los periódicos La Opinión Nacional y Los Andes - se escarneció al levantamiento pierolista y se denostó a su caudillo.

Las fuerzas de la coalición, luego de arrinconar al ejército cacerista en la capital, lanzaron su ataque final el 17 de marzo de 1895. El combate duró dos días, en los que los revolucionarios, apoyados en parte de la población, disputaron palmo a palmo las calles y las torres de las iglesias de la Ciudad de los Reyes. El saldo de este enfrentamiento fue la muerte de alrededor de mil combatientes, los que insepultos fueron enterrados luego de un armisticio promovido por el cuerpo diplomático, en especial José Macchi, delegado apostólico y enviado extraordinario de Su Santidad. Matto, testigo de primera línea del ataque (su casa quedó en el espacio ocupado por las montoneras pierolistas), narró en su libro Boreales el ambiente que vivieron ella y los defensores del cacerismo: "En la capital vivíamos abrasados por una atmósfera calcinada, respirando un aire mefítico por el desborde de las pasiones y el tole tole que se produjo entre milicianos y paisanos, entre los amigos del orden y los partidarios de la revolución" (Matto, 1902, pp. 22-23).

A los pocos días del armisticio, el general Cáceres renunció a la presidencia y marchó inmediatamente fuera del país. Mientras una junta de Gobierno encargada del Ejecutivo desmovilizaba las fuerzas caceristas y organizaba los preparativos para las futuras elecciones, el ejército coalicionista se mantenía ocupando Lima. En estos meses, aquellos hombres armados protagonizaron hechos luctuosos que fueron descritos por la prensa: milicianos y montoneros sin disciplina merodeaban por las calles incluso algunos meses después "con los corbatines á manera de pañuelos al pezcueso, ó sin ellos muchas veces; con la casaca desabotonada, ó con ellos sucios; el pantalón manchado ó roto $[\ldots]$ viajando en carros urbanos [...] sin que los soldados tengan presente sus obligaciones ó sea por que aleguen ignorancias". ${ }^{41}$ A diferencia de un ejército regular, las fuerzas con las que Piérola tomó Lima fueron irregulares, es decir, compuestas por sectores populares urbanos y rurales, muchos de ellos campesinos mestizos, indígenas y afrodescendientes de pequeñas poblaciones

41 La Luz Eléctrica, Lima, 31 de agosto de 1895. 
andinas y costeñas, otros artesanos y sectores plebeyos de las ciudades; no faltaban los bandoleros que, politizados y armados, se plegaban a insurrecciones como estas buscando recompensas clientelares (Velásquez, 2013, pp. 75-78).

El júbilo de los vencedores se expresó en canciones populares ${ }^{42}$ y se atizó también en la prensa de los revolucionarios. En ese ambiente de victoria y de desenfreno, se produjo el 7 de abril el atentado contra La Equitativa y otras imprentas de filiación cacerista. Desde 2 de ese mes se informaba el intento de ataque a la imprenta de La Opinión Nacional, la cual se "ha salvado de ser incendiada" por ser propiedad de la madre un jefe del partido demócrata, ${ }^{43}$ aunque el 7 se presentó un "tumulto [que] ha tocado sus puertas con aires de amenaza", sin que se destruyera más que el rótulo del diario. ${ }^{44}$ En su caso, la policía, un grupo de "dignísimos jóvenes" (notables) y "distinguidos representantes del partido demócrata" intervinieron para contener a los asaltantes. ${ }^{45}$ Ese día también fue asaltado el local del diario El Nacional, de donde se arrebataron una importante cantidad de volúmenes de ediciones propias y de otros diarios ${ }^{46}$ unos días más tarde, luego de la celebración del aniversario del inicio de la insurrección, se hizo "una manifestación hostil delante de [su] imprenta"; ${ }^{47}$ pero no se violentó su maquinaria a pesar que su propietario era Manuel María del Valle, a quien se acusaba públicamente de haber desfalcado el erario durante el gobierno de Cáceres. ${ }^{48} \mathrm{La}$ única imprenta que fue ataca con violencia y destruida fue la de Clorinda Matto a menos de un mes del allanamiento de su casa durante los combates del 17 y el 18 de abril. Ella misma dejó una descripción de la escena y su asombro:

nos trajeron la noticia de que estaban saqueando la imprenta de la calle de Lártiga. Era la nuestra. Los coalicionistas triunfantes estaban practicando el repase con los débiles. Las calles de San Agustín, La Fuente, Lártiga, Plateros estaban sembradas de tipos de imprenta, rotas las puertas del local, inutilizadas las máquinas. Habíamos perdido la última fuente de vida que nos quedaba para la honrosa labor de buscar el pan con el sudor de la frente (Matto, 1902, p. 57).

42 Una de estas rimaba con la música del vals La Reina de España y decía "Si ese tuerto bandido [Cáceres] muriera/y muriese también la melón [su esposa, Antonio Moreno],/el Perú levantara la frente que le cubre ignominia y baldón" (Basadre, 1969, t. X, p. 112).

43 El Leguito Fray José, Lima, 2 de abril de 1895.

44 La Opinión Nacional, Lima, 8 de abril de 1895.

45 La Opinión Nacional (en Matto, 1902, p. 58).

46 Claris Verbis, Lima, 20 de abril de 1895.

47 Claris Verbis, Lima, 21 de abril de 1895

48 Transcripción de la Editorial de Nueva Era, Lima, 8 de abril de 1895 en El Comercio, Lima, 9 de abril de 1895. 
El caso de la destrucción de la imprenta de Clorinda no tiene antecedente conocido y reviste importancia. Fue la única imprenta cacerista que, además de saqueada, su maquinaria fue destruida, ${ }^{49}$ a pesar de los clamores que desde la prensa coalicionista se hicieron para atacar las otras casas editoras fieles al Partido Constitucional. ${ }^{50}$ En la historia del siglo XIX, este sigue siendo un caso particular; por lo general, los Gobiernos, atacados por la prensa de oposición o acorralados por insurrecciones en ciernes cerraban periódicos y encarcelaban a sus redactores, editores o impresores. Sucedió así en 1859 con La Zamacueca, durante el segundo gobierno de Castilla (San Cristóbal, 1945, p. 25), con El Comercio y El Nacional civilistas durante los últimos días del gobierno de José Balta en 1872, con los pierolistas El País y La Tunda a fines del primer gobierno de Cáceres (Gargurevich, 1991, pp. 78-79, 86), y especialmente durante el gobierno de José Antonio Pezet, en el contexto de la revolución en su contra por la firma del Tratado Vivanco-Pareja; se ordenó la clausura y confiscación de imprentas de El Perú y El Estandarte Rojo, así también se evitó la circulación de El Eco del Perú de Arequipa en 1865, cuando ya se encontraba en imprenta, y se encarceló al impresor de La Ley (Arrambide, 2018, pp. 340-346). En todos estos casos, las fuerzas de gobiernos constituidos fueron los protagonistas de estos atentados contra la libertad de imprenta.

Los testimonios indican que la imprenta fue destruida por el "grupo social más ignorante", azuzado por medio de propaganda "la venganza popular". Asunto particular si se considera que durante las revoluciones que movilizaron masivamente a los sectores populares, como las de 1854 y 1865 , hubo atentados de las huestes de los improvisados ejércitos revolucionarios con el apoyo de la población. En 1854, por ejemplo, el Palacio de gGbierno y las casas del presidente caído Echenique y del general Francisco Vidal fueron atacadas y saqueadas por la población limeña (Echenique, 1952, vol. 2, p. 225). En 1865, en Lima, la población atacó y saqueó Palacio de Gobierno y los cuarteles del Ejército que funcionaban en conventos; en el Callao, las fuerzas de Policía y los sectores populares atacaron muchas casas extranjeras sin tocar una sola peruana, en consonancia a la motivación nacionalista de la revolución. No

49 De acuerdo con La Opinión Nacional, los asaltantes "rompieron un gran manparón de vidrios que daba entrada a los talleres, en estos volcaron los cajetines, esparcieron los tipos e inutilizaron la máquina." (Matto, 1902, 57).

50 El 10 y 20 de abril en El Leguito Fray José de "Juan de Arona” se conminaba a la población a ello: "Clausurar las imprentas que sirvieron criminalmente al dictador (empleando para ello la fuerza del pueblo, ya que la policía no lo hace) con el mismo derecho que tuvo Cáceres para clausurar El País, La Tunda y multitud de periódicos no caceristas. El Leguito Fray José, Lima, 10 de abril de 1895. 
hubo en el pasado desbordes revolucionarios en contra de casas editoriales, salvo los apedreamientos promovidos por el clero arequipeño y realizados por mujeres, durante 1873 y 1874, en el contexto de la reforma educativa durante el gobierno de Manuel Pardo que proponía la contratación de preceptores extranjeros y la difusión masiva del El Educador Popular, periódico impreso en Nueva York dirigido por José Arnaldo Márquez y destinado a los preceptores, el que fue quemado públicamente en la ciudad por grupos clericales debido a su posición laica sobre la educación (Mc Evoy, 1997, p. 164).

Entonces ¿por qué hubo ensañamiento en su caso? ¿Por qué los notables del partido demócrata que salieron a la defensa de La Opinión Nacional no protegieron la imprenta de Matto de Turner? La propia Clorinda se explicó este hecho apelando a razones políticas, pues el nuevo gobierno había empleado un régimen de terror contra los vencidos, esto es, sobre aquellos símbolos de una administración que llegó a ser odiada luego de haber sido glorificada. Pero aún más, ella mencionó en Boreales que este ensañamiento era como "el repase con los débiles", es decir, aquellos que no tenían el amparo de las relaciones de sangre - como el caso de La Opinión Nacional_- pero así también por el hecho de pertenecer al sexo débil (recuérdese aquí el cuadro de Ramón Muñiz, de 1888, titulado El repase, en donde se retrata a una mujer defendiendo a un soldado peruano tendido en el suelo del ataque de un soldado chileno). De hecho, la evidencia apunta a que era un escarmiento frente a la condición de ser una mujer que intervino en política. A este respecto, Ricardo Palma confirmaba los costos sociales y personales que debió sufrir Clorinda como mujer:

\begin{abstract}
Mucho aconsejé a mi queridísima comadre Clorinda que no se mezclara en política. Pero me desatendió. Editó periódico para defender algo que no admitía defensa [ilegible] contra lo que el país en masa protestó. Triunfante la revolución se encontró Clorinda rodeada de prevenciones contra su persona, y antes de exponerse a algún desaire social o individual se embarcó para Chile y de ahí ha pasado a Montevideo y Buenos Aires. ${ }^{51}$
\end{abstract}

La destrucción de la imprenta de Matto fue un claro gesto de ensañamiento contra lo que la sociedad patriarcal peruana del siglo XIX consideraba una trasgresión. De esto no dudó la propia militante: "si cometimos el pecado de mezclarnos en política, fue por el derecho que existe de pensar y de ex-

51 Carta de Ricardo Palma a Lola Rodríguez de Tió. Lima, 15 de octubre de 1895 (Palma, 2005, p. 208). 
presar el pensamiento" (Matto, 1902, p. 23). Este no fue el único caso de ataque contra la imprenta dirigida por una mujer, la imprenta de María Jesús Alvarado fue destruida por las fuerzas gubernamentales en 1924. Una última razón pudo plantearse Clorinda sobre el ataque a su imprenta y no era otro que la venganza de los grupos conservadores aliados a Piérola a su posición abiertamente anticlerical de la que ya hemos referido: "aceptando el camino del extranjero para buscar el pan que no podíamos hallar en aquel suelo cargado de venganzas, de atropellos y de cuanto innoble puede producir la comandita del clericalismo con el pierolismo" (Matto, 1902, p. 24).

Piérola tenía fuertes vínculos con la Iglesia católica. Formado en el Convictorio de San Carlos, tuvo siempre una posición favorable a la Iglesia durante toda su carrera política. Inició su vida pública escribiendo para $E l$ Progreso Católico, se convirtió en ministro de Hacienda gracias a si cercanía a José Rufino Echenique, representante militar de las elites sureñas conservadoras. Durante su segundo gobierno, alentó la reactivación de misiones religiosas en la Amazonía y fue un tenaz opositor del matrimonio civil. Aunque republicano y modernizador, Piérola siempre estuvo lejos de ser un liberal. Su retorno al poder implicó un reposicionamiento de la Iglesia católica. Durante la propia guerra civil — de acuerdo con Matto — la intermediación de la Iglesia católica representada por José Macchi, delegado apostólico, en la defección de Cáceres había sido fundamental. Clorinda acusó que Piérola en Santiago de Chile había pactado por adelantado la intervención de Macchi para que fuese abierto y franco propagandista de Piérola como el "único llamado a gobernar a los peruanos" (Matto, 1902, p. 21).

Resulta plausible considerar la reacción eclesiástica y conservadora como último móvil de la destrucción de su imprenta, más si atendemos los antecedentes de las movilizaciones contra El Educador Popular y contra El Perú Ilustrado bajo su dirección y las obras de Matto. En estos ataques había un mensaje para una mujer escritora, anticlerical y vanguardista que exigía su derecho de participar en la vida política en una sociedad patriarcal: no tienes derecho a tener voz propia ni dar voz a otros por medio de la imprenta. Era negar el uso de un recurso tradicionalmente masculino, el que se le expropiaba a Matto; una reacción temerosa, violenta y ejemplar para otras mujeres, a fin de que no se atrevieran a creer que tenían el derecho a cuestionar con voz propia un equilibrio por ese entonces amenazado por los reclamos de la modernidad a los patriarcas laicos y eclesiásticos. 


\section{Fuentes primarias}

Claris Verbis, Lima, 1895

El Perú Ilustrado, Lima, 1890-1891

El Comercio, Lima, 1895

El Correo del Perú, Lima 1873

El Recreo, Cusco, 1876

La Luz Eléctrica, 1895

El Leguito Fray José, Lima, 1895

La Bolsa, Arequipa, 1883-1885

La Opinión Nacional, Lima, 1895

Los Andes, Lima, 1892-1893

\section{Referencias bibliográficas}

Arango-Keeth, F. (2016). Viajera, proscrita y operaria en la factoría de los grandes pueblos: la memoria histórica en Boreales, miniaturas y porcelanas de Clorinda Matto de Turner. En Guardia, S. (Coord.). Seminario Discursos y Prácticas Independentistas de las Mujeres y la Visión de Nación. Historia y Género en América Latina. Lima: CEMHAL.

Arango-Keeth, F. (2012). La construcción del sujeto autobiográfico, histórico y político en la correspondencia epistolar de Clorinda Matto de Turner. En Guardia, S. (Ed.). Escritoras del siglo XIX en América Latina. Lima: CEMHAL.

Arango-Keeth, F. (2009). La reforma social y el discurso liberal en los editoriales de Clorinda Matto de Turner en El Perú Ilustrado (1889-1891). Boletín del Instituto Riva Agüero, 35, 205-222.

Armas, F. (1998). Liberales, protestantes y masones. Modernidad y tolerancia religiosa. Perú, siglo XIX. Cusco: CBC.

Arrambide, V. (2018). Prensa y revolución: los periódicos durante las guerras civiles de 1865 y 1867. En McEvoy, C. y Rabinovich, A. (Eds.). Tiempo de guerra. Estado, nación y conflicto armado en el Perú, siglos XVII-XIX (pp. 335-363). Lima: Instituto de Estudios Peruanos.

Basadre, J. (1969). Historia de la República del Perú 1822-1933 (t. X). Lima: Editorial Universitaria.

Berg, M. G. (2010). Prólogo. En Matto, C. Viaje de recreo. España, Francia, Inglaterra, Italia, Suiza, Alemania. Stockcero. 
Berg, M. G. (1997). Clorinda Matto de Turner: periodista y crítica (Perú, 1852-1909). En Osorio, B. y María, J. (Eds.). Las desobedientes: mujeres de nuestra América. Bogotá: Panamericana Editorial.

Chocano, M. (2010). Lima masónica: las logias simbólicas y su progreso en el medio urbano a fines del siglo XIX. Revista de Indias, LXX(249), 409-444.

Denegri, F. (2004). El abanico y la cigarrera: la primera generación de mujeres ilustradas en el Perú. Lima: Instituto de Estudios Peruanos.

Echenique, J. (1952). Memorias para la historia del Perú (1808-1878) (vol. 2). Lima: Editorial Huscarán.

Ferreira, R. (s/f). La profesionalización de la periodista y escritora: Clorinda Matto de Turner obrera del pensamiento. En: Biblioteca Virtual Miguel de Cervantes Disponible en: http://www.cervantesvirtual.com/obra-visor/la-profesionalizacionde-la-periodista-y-escritora-clorinda-matto-de-turner-obrera-del-pensamiento/ html/9be24fd4-497d-11e0-b1fb-00163ebf5e63_3.html.

Ferreira, R. (s/f). Clorinda Matto de Turner, infatigable obrera del pensamiento. Recuperado de: https://docplayer.es/44302502-Clorinda-matto-de-turner-infatigable-obrera-del-pensamiento.html.

Ferreira, R. (2005). Clorinda Matto de Turner, novelista y los aportes de Antonio Cornejo Polar al estudio de la novela peruana. Revista de Crítica Literaria latinoamericana, XXXI(62), 27-51.

Forment, C. (2012). La formación de la sociedad civil y la democracia en el Perú. Lima: Fondo Editorial de la Pontificia Universidad Católica del Perú.

Gargurevich, J. (1991). Historia de la prensa peruana, 1594-1990. Lima: La Voz Ediciones.

Huárag, E. (2013). La narrativa y la historia en el Perú republicano: conjunciones y disyunciones. En Huárag, E. Violencia social y política en la narrativa peruana. Lima: Fondo Editorial de la Pontificia Universidad Católica del Perú, Instituto Riva Agüero.

Klaiber, J. (1995). La Iglesia en el Perú: su historia social desde la Independencia. Lima: Fondo Editorial de la Pontificia Universidad Católica del Perú.

Karén, P. (2004). Nación y sociedad en la historia del Perú. Lima: Instituto de Estudios Peruanos.

Küppers, G. (1989). Peruanische Autorinnen vor der Jahrhundertwende: Literatur und Publistik als Emaimpaûonsprojekt bei Clorinda Matto de Turner. Fráncfort del Meno, Nueva York, París: Peter Lang. 
Mannarelli, M. E. (2013). Las mujeres y sus propuestas educativas (18701930). Colección Historia del Pensamiento Educativo (vol. 9). Lima: Derrama Magisterial.

Matto, C. (2016). Las obreras del pensamiento en la América del Sur [lectura hecha por la autora en el Ateneo de Buenos Aires, el 14 de diciembre de 1895]. Asparkía, 29, 169-179.

Matto, C. (1994). Aves sin nido. Caracas: Fundación Biblioteca Ayacucho.

Matto, C. (1974). Índole. Lima: Instituto Nacional de Cultura.

Matto, C. (1902). Boreales, miniaturas y porcelanas. Buenos Aires: Imprenta de Juan A. Alsina.

Matto, C. (1974). Las obreras del pensamiento en la América del Sur. Ciudad: Editorial.

Matto, C. (1890). Bocetos al lápiz de Americanos Célebres. Lima: Imprenta Bacigalupi.

Matto, C. (1882). Carta de Clorinda Matto de Thurner al Señor Presidente Contra Almirante D. Lizardo Montero. Tinta, 11 de setiembre de 1882. Archivo personal de Luis Guzmán Palomino.

Mc Evoy, C. (1997). La utopía republicana: ideales y realidades en la formación de la cultura política peruana (1871-1919). Lima: Fondo Editorial de la PUCP.

Miserés, V. (2009). De artesana de la palabra a obrera del pensamiento: Clorinda Matto de Turner y sus reflexiones en torno a la prensa en La Bolsa de Arequipa (1884). Boletín de Instituto Riva Agüero, 35, 171-188.

Mücke, U. (2010). Política y burguesía en el Perú. El Partido Civil antes de la guerra con Chile. Lima: Instituto Francés de Estudios Andino, Instituto de Estudios Peruanos.

Ortiz, C. (2007). El pensamiento político de Clorinda Matto de Turner. Investigaciones Sociales, XI(18), 379-397.

Pacheco, J. (2017). La escritora y sus detractores: Clorinda Matto de Turner (1890-1895). Desde el Sur. Revista de Ciencias Humanas y Sociales de la Universidad Científica del Sur, 10(1), 142-143.

Palma, R. (2005). Epistolario general (1892-1904). En Matto, C. Obras completas (t. VIII, vol. 2). Lima: Universidad Ricardo Palma, Editorial Universitaria.

Peluffo, A. (2005). Lágrimas andinas: sentimentalismo, género y virtud republicana en Clorinda Matto de Turner. Pittsburgh: PA Instituto Internacional de Literatura Iberoamericana, Universidad de Pittsburgh.

Portugal, A. M. (1999). El periodismo militante de Clorinda Matto de Turner. En Zegarra, M. (Comp.). Mujeres y género en la historia del Perú. Lima: CENDOC.

San Cristóbal, E. (1945). El mariscal Ramón Castilla y el periodismo de su época. Lima: Compañía de Impresiones y Publicidad. 
Sotomayor, E. (2014). Satisfecha y orgullosa, aunque sea impropio. Las veladas literarias de Clorinda Matto de Turner (1887-1891?) (tesis de maestría). Lima: Pontificia Universidad Católica del Perú.

Vargas, M. (2009). Clorinda Matto: constructora de la nación en El Perú Ilustrado (18891891) y constructora de América en el Búcaro Americano (1896-1908). Boletín del Instituto Riva Agüero, 35, 223-242.

Velásquez, D. (2015). Una historia de los registros del estado civil en el siglo XX. En RENIEC. Identidad digital. La identificación desde los registros parroquiales al DNI electrónico. Lima: RENIEC.

Velásquez, D. (2013). La reforma militar y el gobierno de Nicolás de Piérola. El Ejército moderno y la construcción del Estado peruano (tesis de maestría). Lima: Universidad Nacional Mayor de San Marcos. 